\title{
Extraction and Characterization of Pectic Polysaccharides from Chaenomeles sinensis Fruit by Hot Compressed Water
}

\author{
Hua-Min Liu, ${ }^{\mathrm{a}}$ Ya-Nan Wei, ${ }^{\mathrm{a}}$ Yuan-Yuan Yan, ${ }^{\mathrm{a}}$ Min Wu, ${ }^{\mathrm{b}}$ Guang-Yong Qin, ${ }^{\mathrm{b}}$ and \\ Xue-De Wang ${ }^{\text {a, } *}$
}

The effects of extraction conditions on the yield of polysaccharides from the fruit of Chaenomeles sinensis (FCS) using a hot compressed water method were investigated. The results showed that an appropriately high temperature $\left(150{ }^{\circ} \mathrm{C}\right)$ and a moderate extraction time $(45 \mathrm{~min})$ at a material to water ratio of 1 to $10 \mathrm{~g} / \mathrm{mL}$ led to a high yield of alcohol precipitation polysaccharide $\left(P_{A}\right)$. The purified polysaccharides (CSP-1, CSP-2, and CSP-3) were successfully obtained using a DEAE-52 chromatographic column. Chemical analysis showed that CSP-2 and CSP-3 were homogenous and exhibited characteristics of esterified pectins, whereas CSP-2 mainly consisted of galacturonic acid (GalA), galactose (Gal), arabinose (Ara), rhamnose (Rha), and mannose (Man) with an average molecular weight of $59.1 \mathrm{kDa}$. Furthermore, CSP-1 possessed stronger antioxidant ability according to DPPH scavenging and reducing power compared with CSP-2 and CSP-3. However, it was weaker with respect to $\mathrm{OH}$ scavenging. The technical data presented in this study could help the industry make use of polysaccharides from FCS as a source of pectin for a range of pharmaceutical, culinary, and cosmetic products.

Keywords: Chaenomeles sinensis fruit; Pectic polysaccharide; Hot compressed water; Structure; Antioxidant activities

Contact information: a: College of Food Science and Technology, Henan University of Technology, Zhengzhou 450001, China; b: Institute of Physical Science and Engineering, Zhengzhou University, Zhengzhou 450001, China; *Corresponding author: wangxuede1962@126.com

\section{INTRODUCTION}

Chaenomeles sinensis is a deciduous spiny shrub or semi-evergreen tree native to China and widely distributed throughout China, Japan, and Korea. The ripe fruit of Chaenomeles sinensis (FCS) is oval-shaped and golden in color. Its flesh is hard, dry, sour, and astringent due to its high amount of lignin. Thus, the flesh of FCS fruits is seldom consumed fresh but is most often consumed in processed forms (e.g., drinks, jam, jelly, and candy). As a traditional oriental medicine, the crude extracts from FCS can be used to treat sore throat, influenza, anaphylaxis, and diabetes (Kim et al. 2013).

Polysaccharides isolated from natural materials have gained attention because they possess antioxidant, antitumor, and anti-cancer activities (Chen and Huang 2018). Pectin is a polysaccharide found in the middle lamella, primary cell, and secondary walls. It is used as a gelling and/or thickening agent in home canning and the food industry. Pectin possesses extensive pharmacological activities. Many attempts have been made to extract its bioactive components such as phenols from FCS (Kim et al. 2013; Fagioli et 
al. 2019).

The extraction and properties of pectic polysaccharides from FCS remain poorly investigated. A hot acid method is conventionally used to extract commercial pectin. However, this method requires a long extraction time, significant amounts of energy and solvent, and creates environmental pollutants. More efficient and eco-friendly green extraction methods have been developed, such as ultrasound-assisted or microwaveassisted extraction, accelerated solvent extraction, hot compressed water extraction, supercritical fluid extraction, and enzymatic extraction.

The hot compressed water method (HCW), commonly referred to as the subcritical water extraction, has been used to extract pectin from many materials (Miyazawa and Funazukuri 2004; Wang et al. 2017). Water under subcritical conditions remains in a liquid state, but it manifests changes in some physicochemical properties such as density, polarity, electrical properties, dissociation constant, surface tension, viscosity, diffusivity, and solvency (Zhao et al. 2013). During the HCW procedure, the $\mathrm{pH}$ of the reaction system is reduced to the range of 3 to 4 due to the release of acetic acid from O-acetyl groups within the polysaccharides. When the temperature rises, the dielectric constant of water decreases and so does its polarity (Chen et al. 2010). Therefore, it is possible to use HCW to extract polar, moderately polar, and nonpolar substances (Zhao et al. 2013). HCW has been widely used in the extraction of polysaccharides, glycoside, oil, nutraceuticals, and proteins (Liu et al. 2016).

The object of this study was to investigate the effects of HCW extraction conditions on the yields of pectic polysaccharides and elucidate their physical properties and chemical structures. Finally, the antioxidant ability of the polysaccharides was also assessed in vitro.

\section{EXPERIMENTAL}

\section{Materials}

Ripe FCS was purchased in October from a farm in Tanghe (Nanyang, China). The fruits were cleaned to remove the seeds and cut into $5 \mathrm{~mm}$ slices. The slices were freeze dried, ground to a fine powder by high speed rotary cutting, and then sifted through a $0.45 \mathrm{~mm}$ mesh screen. The powder was dewaxed with a toluene and ethanol ratio ( 2 to 1 , volume per volume) in a Soxhlet extraction apparatus for $12 \mathrm{~h}$ at $60{ }^{\circ} \mathrm{C}$. The dewaxed sample was air dried for $24 \mathrm{~h}$ and stored in a freezer at $-4{ }^{\circ} \mathrm{C}$ until use. All reagents and chemicals were of analytical grade and were commercially purchased unless otherwise stated.

\section{Methods}

Extraction and purification of polysaccharides

Polysaccharides were extracted from the powder sample using a previously reported method (Liu et al. 2016). For a typical run, $20 \mathrm{~g}$ of material and $200 \mathrm{~mL}$ of distilled water were added into a $350 \mathrm{~mL}$ pressure glass reactor. After the extraction was completed, the aqueous phase and solid residue (SR) were separated using a vacuum filtration flask. The filtrate was concentrated to a certain volume under reduced pressure at $50{ }^{\circ} \mathrm{C}$ and precipitated with 4 volumes of ethanol for $12 \mathrm{~h}$ at $4{ }^{\circ} \mathrm{C}$. The precipitates were collected by filtration and washed with $80 \%$ ethanol; these precipitates were defined as polysaccharide $\mathrm{A}\left(\mathrm{P}_{\mathrm{A}}\right)$. The ethanol soluble fraction was gathered and concentrated by 
rotary evaporation at $45{ }^{\circ} \mathrm{C}$ and defined as polysaccharide $\mathrm{B}\left(\mathrm{P}_{\mathrm{B}}\right)$. Lastly, $\mathrm{SR}, \mathrm{P}_{\mathrm{A}}$, and $\mathrm{P}_{\mathrm{B}}$ were lyophilized for further analysis or dried at $105{ }^{\circ} \mathrm{C}$. The yields were calculated as follows in Eq. 1,

$$
Y_{P}=\left[W_{P} \div W_{d}\left(1-Y_{w}\right)\right] \times 100
$$

where $Y_{P}$ is the yield of $\mathrm{P}_{\mathrm{A}}, \mathrm{P}_{\mathrm{B}}$, and $\mathrm{SR}(\mathrm{wt} \%) ; W_{P}$ is the weight of $\mathrm{P}_{\mathrm{A}}, \mathrm{P}_{\mathrm{B}}$, and SR $(\mathrm{g}) ; W_{d}$ is the weight of raw material $(\mathrm{g}) ; Y_{w}$ is the moisture content within the raw material (wt $\%)$.

For the purification process, the crude polysaccharides from the process (CSP) were re-dissolved in distilled water and centrifuged. Then a sevage solution (chloroform: n-butyl alcohol equals 4 to 1 , volume per volume) was added to remove the proteins. After being decolored by a macroporous resin AB-8, the CSP polysaccharide was dialyzed, freeze dried, and then purified with a cellulose DEAE-52 column $(2.6$ by 40 $\mathrm{cm})$ pre-equilibrated with distilled water. Fractions were eluted stepwise with distilled water, $0.1 \mathrm{~mol} / \mathrm{L} \mathrm{NaCl}$, and $0.2 \mathrm{~mol} / \mathrm{L} \mathrm{NaCl}$ at a flow rate of $1.1 \mathrm{~mL} / \mathrm{min}$, and then collected for $5 \mathrm{~min}$ in each tube using an automatic fraction collector. The polysaccharide content was determined by the phenol sulfuric acid method at $490 \mathrm{~nm}$, and the elution curves were plotted. The products of three elution's were pooled, concentrated, and dialyzed against running water for 2 days and distilled water for $2 \mathrm{~h}$ to remove small molecular substances (molecular weight 3,500 Da). Finally, the three fractions were freeze dried and then stored in a desiccator at room temperature for further studies.

\section{Monosaccharide composition analysis}

The method determination of monosaccharide compositions by high performance anion exchange chromatography (Dionex, ICS-3000, Shanghai, China) equipped with an AS50 auto-sampler and a Carbopac PA-20 column $(4 \times 250 \mathrm{~mm}$, Dionex $)$ were described by Wang et al. (2017).

\section{Structural characterization}

The homogeneity and molecular weight of the polysaccharide fraction were determined using gel permeation chromatography (GPC) (Agilent, PLGPC50, Shanghai, China), matched with a KW 402.5-4F column (300 mm by $4.6 \mathrm{~mm}$ by $5 \mu \mathrm{m}$, Shodex, Shanghai, China). Samples (1 mg) were dissolved in $1 \mathrm{~mL}$ of distilled water and then passed through a $0.22 \mu \mathrm{m}$ filter. For GPC analysis, $10 \mu \mathrm{L}$ of the solution was injected. The solution was eluted with distilled water at a flow rate of $0.3 \mathrm{~mL} / \mathrm{min}$ under a column temperature of $30{ }^{\circ} \mathrm{C}$. Polyethylene oxide (molecular weights of 25.8, 40.1, and 52.9 $\mathrm{kDa})$ was also analyzed under the same conditions to establish the standard curve. The molecular weight $\left(M_{w}\right)$ was calculated from the standard curve using Eq. 2,

$$
\begin{aligned}
& \log M_{w}=5.524-0.1062 t \\
& R^{2}=0.996074
\end{aligned}
$$

where $M_{w}$ is the molecular weight ( $\mathrm{g} /$ mole), $t$ is the retention time, and $\mathrm{R}^{2}$ is the coefficient of determination.

The UV spectra were obtained on a T6 UV-Vis spectrophotometer (Puxi, China) in the range of 200 to $600 \mathrm{~nm}$ at room temperature. The Fourier transform infrared (FTIR) spectroscopy spectrum was recorded on a WQF-510 FT-IR Microscope (North Points Rayleigh, Beijing, China) within the frequency range of 450 to $4000 \mathrm{~cm}^{-1}$ using 16 scans 
recorded at a resolution of $4 \mathrm{~cm}^{-1}$. One $\mathrm{mg}$ sample was mixed with $50 \mathrm{mg}$ of $\mathrm{KBr}$ powder, thoroughly ground, and then pressed into a $1 \mathrm{~mm}$ pellet. The degree of esterification (DE) has been determined according to Eq. 3,

$$
D E(\%)=\left[A_{1745} \div\left(A_{1745}+A_{1615}\right)\right] \times 100 \%
$$

where $A_{1745}$ and $A_{1615}$ are the peak area at $1745 \mathrm{~cm}^{-1}$ and $1615 \mathrm{~cm}^{-1}$, respectively.

According to previous research regarding the methylation analysis of acidic polysaccharides, the carboxyl portion of the molecule should be first reduced and then methylated (Pettolino et al. 2012). Complete methylation was confirmed by the disappearance of the $\mathrm{OH}$ band (3200 to $3700 \mathrm{~cm}^{-1}$ ) from the FTIR spectrum. The methylated product was hydrolyzed, reduced with $\mathrm{NaBH}_{4}$, and then acetylated with acetic anhydride. Finally, the partially methylated alditol acetates (PMAAs) were analyzed by an HP 6890 GC-MS system (Agilent, Shanghai, China) fitted with a BPX70 column and coupled with an HP 5973 MS instrument.

The ${ }^{1} \mathrm{H}$ and ${ }^{13} \mathrm{C}$ nuclear magnetic resonance (NMR) spectra were obtained using a Bruker Advance $500 \mathrm{MHz}$ NMR spectrometer (III HD, Karlsruhe, Germany). Homogeneous samples $\left(30 \mathrm{mg}\right.$ ) were dissolved in $0.7 \mathrm{~mL}$ of $\mathrm{D}_{2} \mathrm{O}$ with overnight stirring at room temperature. The NMR spectra were recorded at room temperature.

\section{Antioxidant capacity in vitro}

The $\mathrm{OH}$ scavenging activity was assessed according to a previous report ( $\mathrm{Pu}$ et al. 2016 ) with some modifications. One $\mathrm{mL}$ of various concentrations ( 0.1 to $2 \mathrm{mg} / \mathrm{mL}$ ) of the sample or vitamin $\mathrm{C}\left(\mathrm{V}_{\mathrm{C}}\right)$ was added successively into isometric ferrous sulfate (6 $\mathrm{mM})$, salicylic acid ethanol $(6 \mathrm{mM})$, and hydrogen peroxide $(6 \mathrm{mM})$. After incubating at $37^{\circ} \mathrm{C}$ for $1 \mathrm{~h}, 4 \mathrm{~mL}$ of the reaction mixture was assessed for absorbance at $510 \mathrm{~nm}$. For the control, the sample was replaced by distilled water. Radical scavenging activity was determined by the previous method with some modifications ( $\mathrm{Pu}$ et al. 2016). The reaction mixture contained $2 \mathrm{~mL}$ DPPH solution $(0.04 \mathrm{mg} / \mathrm{mL}$ in anhydrous ethanol) and $2 \mathrm{~mL}$ of various concentrations $(0.1$ to $2 \mathrm{mg} / \mathrm{mL})$ of the sample or $\mathrm{V}_{\mathrm{C}}$. After vigorous shaking, the solutions were incubated at room temperature in the dark for $30 \mathrm{~min}$ and then tested at $517 \mathrm{~nm}$. For the control, the sample was substituted by distilled water.

For reducing power tests, $0.5 \mathrm{~mL}$ of various concentrations $(0.1$ to $2 \mathrm{mg} / \mathrm{mL})$ of sample or $\mathrm{V}_{\mathrm{C}}$ mixed with $1 \mathrm{~mL}$ phosphate buffer $(0.2 \mathrm{M}, \mathrm{pH}=6.6)$, and $1 \mathrm{~mL}$ potassium ferricyanide solution $(1 \%, \mathrm{w} / \mathrm{v})$ were incubated at $50{ }^{\circ} \mathrm{C}$ for $20 \mathrm{~min}$. The reactions were terminated by trichloroacetic acid $(10 \%, \mathrm{w} / \mathrm{v})$, and then solutions were centrifuged for 10 min at $3000 \times g .1 .5 \mathrm{~mL}$ of supernatant was mixed with isovolumetric distilled water and ferric chloride $(0.1 \%, w / v)$. The absorbance of samples was measured at $700 \mathrm{~nm}$. Distilled water took the place of samples for the control. The scavenging rate was calculated according to Eq. 4,

$$
\text { Scavenging rate }(\%)=\left(1-\left(A_{t} \div A_{0}\right)\right) \times 100 \%
$$

where $A_{0}$ is the absorbance of the control and $A_{l}$ is the absorbance of the samples per $\mathrm{V}_{\mathrm{C}}$.

\section{RESULTS AND DISCUSSION}

\section{Effect of Extraction Conditions on Product Yields}

The effects of temperature and extraction time on the yield of products are shown 
in Fig. 1A and B. In the trials, the highest yield of $\mathrm{P}_{\mathrm{A}}(14.4 \pm 0.4 \%)$ in Fig. $1 \mathrm{~A}$ was obtained at $150{ }^{\circ} \mathrm{C}$. The yield of $\mathrm{P}_{\mathrm{A}}$ was also positively correlated with an increased duration initially, reaching $14.0 \pm 0.8 \%$ within $45 \mathrm{~min}$, as shown in Fig. 1B. Higher temperature and longer extraction time resulted in a lower SR yield and higher $\mathrm{P}_{\mathrm{A}}$ yield, due to thermal degradation of SR. During extraction, large chain compounds such as cellulose, hemicellulose, and lignin are typically broken down into smaller and simpler molecules, which can dissolve to form water-soluble polysaccharides (Yuliansyah et al. 2010). However, $P_{A}$ is further decomposed by dehydration and fragmentation reactions if the treatment with $\mathrm{HCW}$ is prolonged. The yield of $\mathrm{P}_{\mathrm{A}}$ decreased when the temperature exceeded $150{ }^{\circ} \mathrm{C}$ or when the time was longer than $45 \mathrm{~min}$. The $\mathrm{P}_{\mathrm{B}}$ yield tended to drop slightly at the beginning, followed by a remarkable rise from $14.4 \pm 0.6 \%$ to $22.7 \pm 0.2 \%$ with temperatures of 135 to $165{ }^{\circ} \mathrm{C}$ in Fig. 1A. After 45 min, there was also a slight increase of $\mathrm{P}_{\mathrm{B}}$ yield. There might be a conversion of $\mathrm{P}_{\mathrm{A}}$ to $\mathrm{P}_{\mathrm{B}}$, induced by the longer-term degradation of $\mathrm{P}_{\mathrm{A}}$ (Liu et al. 2016). However, those conditions could also destroy the structures and promote the decomposition of polysaccharides into smaller molecules. There was a slight increase of SR at $165^{\circ} \mathrm{C}$, which was interpreted as the re-condensation of soluble components that originated from lignin (Alvira et al. 2010). Based on these results, the optimum extraction conditions for $\mathrm{P}_{\mathrm{A}}$ were $150{ }^{\circ} \mathrm{C}$ and $45 \mathrm{~min}$.
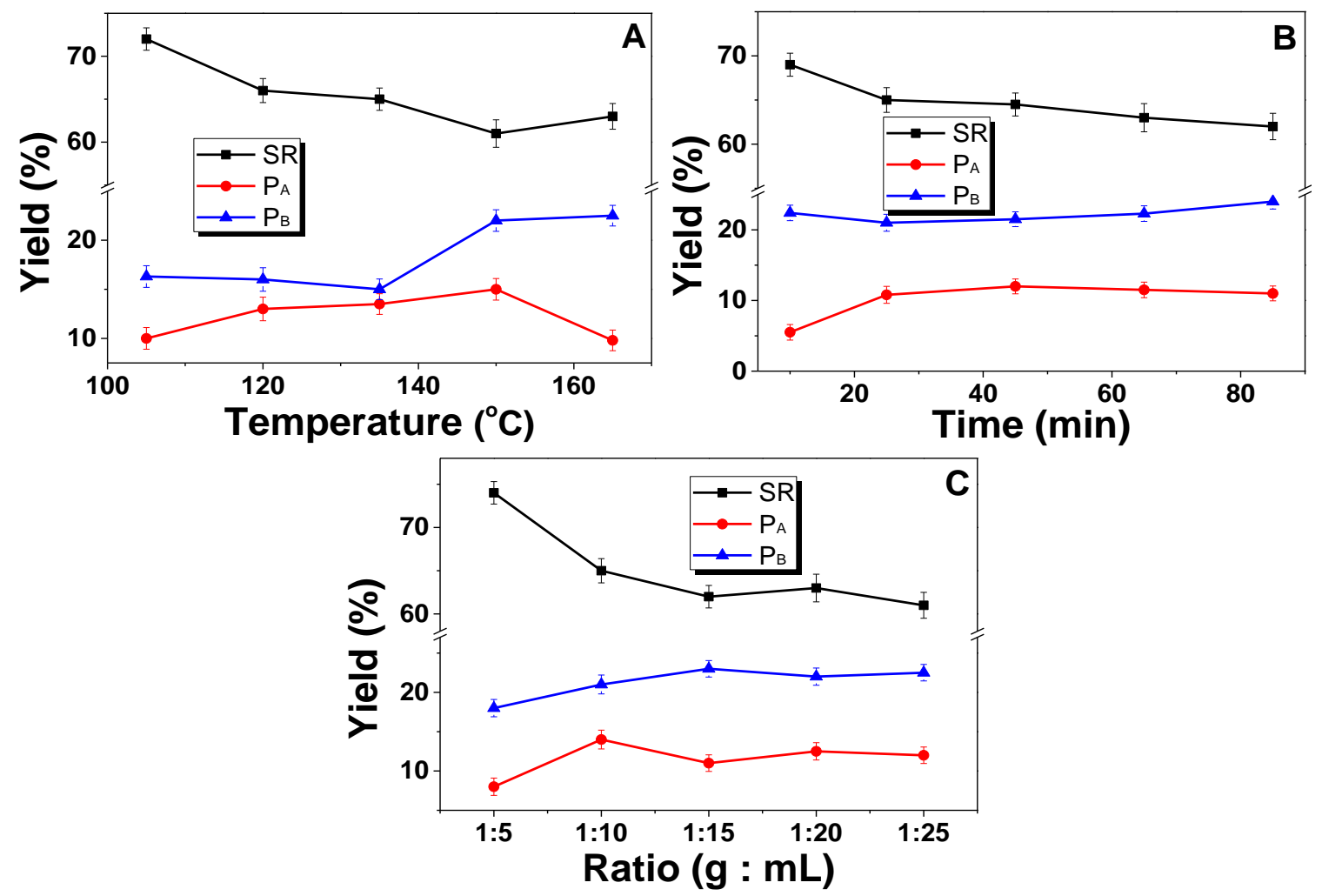

Fig. 1. Effect of extraction conditions on product yields based on raw material: $(A)$ temperature $\left(105\right.$ to $165^{\circ} \mathrm{C}$ ), extraction time $45 \mathrm{~min}$, and solid to liquid ratio of 1 to 10 ; (B) extraction time (10 to $85 \mathrm{~min}$ ), temperature $120^{\circ} \mathrm{C}$, and a solid to liquid ratio of 1 to $10 ;(\mathrm{C})$ solid to liquid ratio (1 to 5 and 1 to 30), extraction time $45 \mathrm{~min}$, and a temperature of $120^{\circ} \mathrm{C}$

The relative content of solvent is another important factor in the treatment of the raw material. As shown in Fig. 1C, the yield of SR notably decreased as the solid/liquid 
ratio $(\mathrm{g} / \mathrm{mL})$ was decreased from $1: 5$ to $1: 15$. The yield continued to decrease slightly, as the material to water ratio approached the range 1:15 to $1: 30$. The yield of $\mathrm{P}_{\mathrm{A}}$ first increased and then decreased. A valley in the peak yield $(14.0 \pm 0.8 \%)$ can be observed at a 1:10 ratio, with a plateau region observed thereafter. One explanation of this result was that the large content of water encouraged diffusion of the solvent into the cells, as well as more rapid dissolution of the polysaccharide (Zhao et al. 2013; Xu et al. 2016). However, increasing the solvent had little effect on the yield after $\mathrm{P}_{\mathrm{A}}$ reached maximum solubility. Presumably, this is because an excess of water absorbs cavitation energy from the extraction system, which negatively influences the breakage of cell walls and mass transmission (Samavati 2013). From an economic perspective, a material to water ratio of 1:10 is apparently optimal and was selected here for subsequent study.

Among the three extraction factors studied, an appropriately high temperature $\left(150{ }^{\circ} \mathrm{C}\right)$, moderate extraction time $(45 \mathrm{~min})$, and a 1 to 10 ratio of material to water were found to exert a positive effect on $\mathrm{P}_{\mathrm{A}}$ extraction. Similar conditions have been shown to be ideal for extracting pectic polysaccharides from apple pomace (Wang and Lv 2014).

\section{Purification and Analysis of Molecular Weight (Mw)}

$\operatorname{CSP}\left(\mathrm{P}_{\mathrm{A}}\right)$ produced under the optimized conditions $\left(150{ }^{\circ} \mathrm{C}, 45 \mathrm{~min}, 1\right.$ to 10$)$ was used for further purification and structural characterization. The crude polysaccharide precipitated by ethanol contained considerable impurities, such as polyphenols, flavonoids, and proteins. After deproteinization and de-coloration, samples were further purified by anion exchange chromatography via DEAE-52. One neutral polysaccharide and two acidic components designated as CSP-1, CSP-2, and CSP-3 were obtained. CSP1 was a neutral polysaccharide because it was eluted by water, while CSP-2 and CSP-3 were known to represent acidic polysaccharides because they were eluted by $\mathrm{NaCl}$ solutions. In terms of conventional physicochemical properties, the purified polysaccharides were flocculent, white, odorless, soluble in water and DMSO, and only slightly soluble in organic solvents.

The homogeneity and $M_{w}$ of acidic polysaccharides were evaluated by GPC. As illustrated in Fig. 2, CSP-2 and CSP-3 showed single, symmetrical, and narrow peaks with elution times of $7.08 \mathrm{~min}$ and $7.17 \mathrm{~min}$, respectively. Thus, CSP-2 and CSP-3 were regarded as homogeneous polysaccharides. Their average $M_{w}$ values were estimated to be $59.1 \mathrm{kDa}$ and $57.9 \mathrm{kDa}$, respectively. However, CSP-1 was not homogenous because it was eluted at three peaks, as can be seen in Fig. 2.
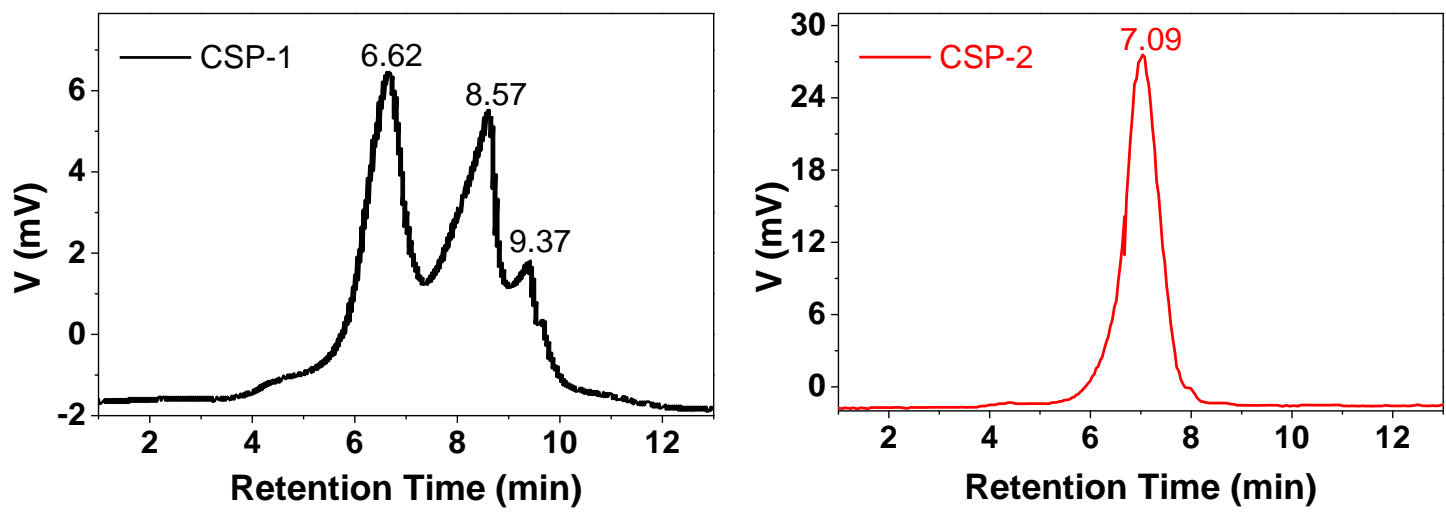


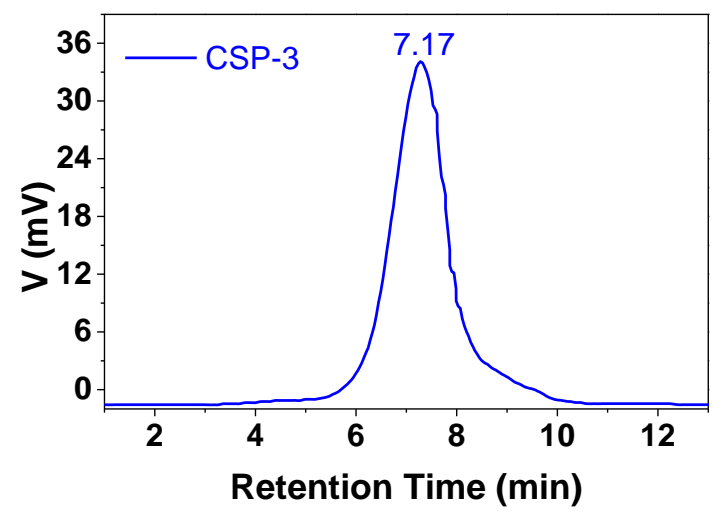

Fig. 2. GPC analysis of CSP-1, CSP-2 and CSP-3

\section{Monosaccharide Composition}

As shown in Table 1, CSP-1, CSP-2, and CSP-3 were comprised of similar types of monosaccharides; namely, Ara, Gal, Glu, Man, Rhm, and GalA. CSP-1 was highly enriched with Ara (45.4\%), followed by Gal (19.1\%), and Glu (14.4\%). A few uronic acid molecules (6.2\%) were present in CSP-1, indicating that it was a neutral polysaccharide. The primary uronic acid in CSP-1 was GluA. As a comparison, the CSP eluted from DEAE-sepharose by water from Chaenomeles speciosa using the hot water method only contained four neutral monosaccharides: Glc, Gal, Rha, and Ara (Xie et al. 2015). The variation in the amount of sugars was most likely related to the differences of species between the presented studied material and Chaenomeles speciosa. In addition, the high temperature and pressure could contribute to different degrees of degradation. During the process of biomass hydrolysis within hot compressed water, Ara was shown to be hydrolyzed and degraded first (Wang et al. 2014), which led to the high amount of Ara in the polysaccharides obtained.

CSP-2 and CSP-3 primarily contained GalA, followed by Gal and Ara with molar ratios of 4.6:2.4:1 and 6.3:0.5:1.5, respectively. The molar ratio of GalA reached 53.2, and its relative proportion increased to $73.6 \%$. Both figures are typical of the monosaccharides of pectins. These results suggest that the backbones of the two fractions comprised homogalacturonan $(\mathrm{HG})$ and rhamnogalacturonan $(\mathrm{RG})$ carrying side chains containing primarily Gal and Ara. The molar ratio of GalA per (Rha + Gal + Ara + Man + Glu) in CSP-3 (2.8) was higher than in CSP-2 (1.4), demonstrating that CSP-3 was more linear. The molar ratio of (Ara + Gal) per Rha reflected the degree of side chain branching, so it seemed that longer side chains were attached to the RG portion in CSP-2 (Ferreira et al. 2006). In addition, the small amount of Man and Glu bound to the side chains might originate from hemicelluloses or cellulose. Two uronic acids could be detected, with contents of $6.2 \%, 53.2 \%$, and $78.0 \%$ in CSP-1, CSP-2, and CSP-3, respectively. Uronic acid content increased with increasing salting strength of the eluant. The same trend could be seen in Sadeqs' research on Mangifera pajang fruits (Al-Sheraji et al. 2012). Clearly, CSP-2 and CSP-3 are pectic polysaccharides and contain more GalA than apple pomace extracted by HCW (Wang and Lv 2014). 
Table 1. Monosaccharide Components of CSP-1, CSP-2, and CSP-3

\begin{tabular}{|c|c|c|c|c|c|c|c|c|}
\hline \multirow{2}{*}{ Fraction } & \multicolumn{7}{|c|}{ Molar composition ${ }^{\mathrm{a}}$ (\% based on total sugar) } \\
\cline { 2 - 9 } & GalA & Ara & Gal & Glu & Rhm & Man & GluA & Xyl \\
\hline CSP-1 & 0.4 & 45.4 & 19.1 & 14.4 & 4.3 & 5.6 & 5.8 & 5.0 \\
\hline CSP-2 & 53.2 & 11.6 & 27.7 & 4.5 & 2.4 & 0.6 & - & - \\
\hline CSP-3 & 73.6 & 17.7 & 6.0 & 1.2 & 1.5 & 0.1 & - & - \\
\hline $\begin{array}{l}\text { aGalA: galacturonic acid; Ara: arabinose; Gal: galactose; GluA: Glu: glucose; Rhm: rhamnose; } \\
\text { Man: mannose; glucuronic acid; Xyl: Xylose }\end{array}$ \\
\hline
\end{tabular}

\section{Analysis of UV and FTIR Spectra}

As shown in Fig. 3A, there were no peaks at 280 or $260 \mathrm{~nm}$, demonstrating the absence of proteins and nucleic acids in all three samples. All FTIR spectrograms in Fig. 3B present typical characteristics of polysaccharides. The spectra of the three polysaccharides were almost identical, which indicates that they had similar chemical structures.
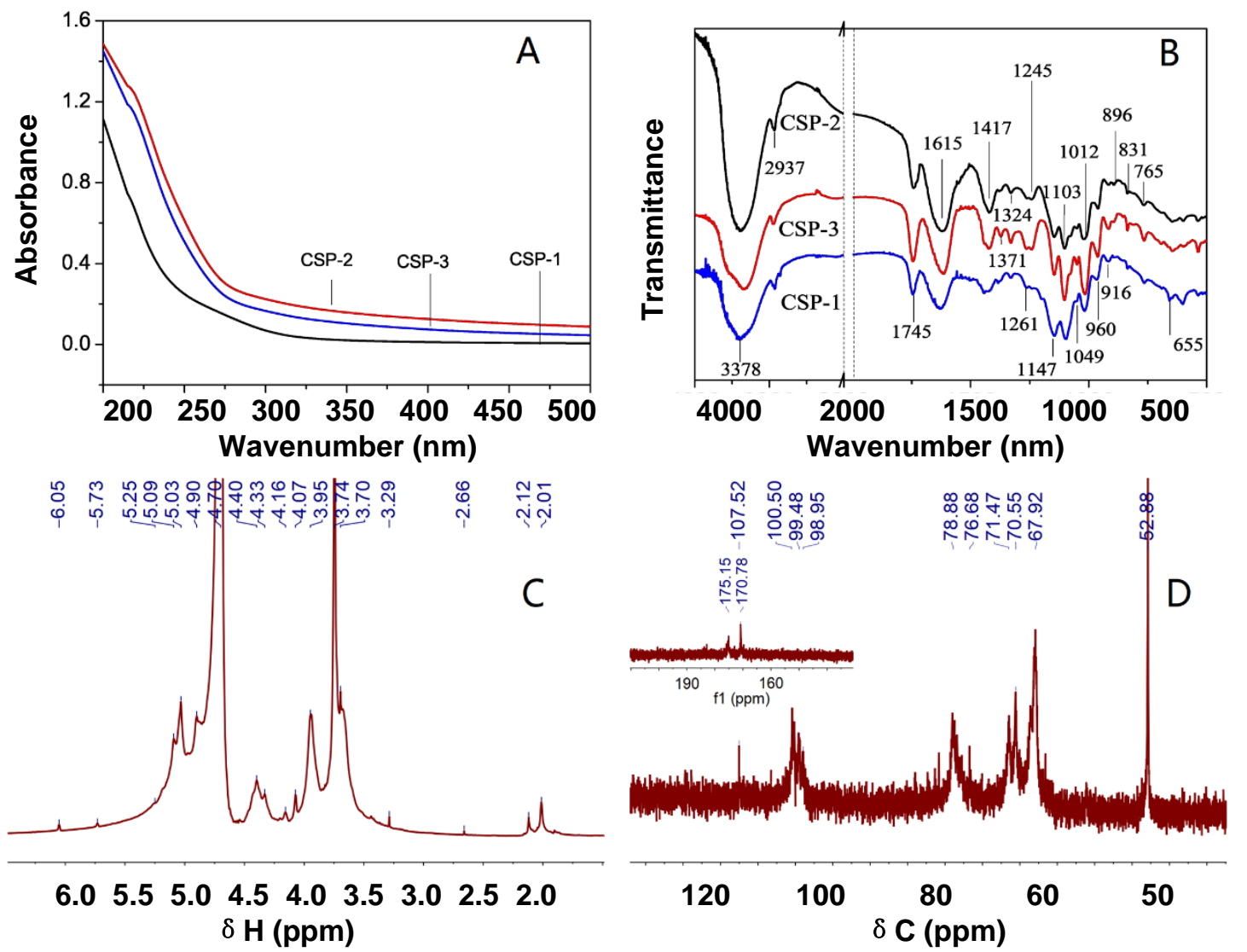

Fig. 3. (A-B) UV and FTIR spectra of CSP-1, CSP-2, CSP-3; (C-D) ${ }^{1} \mathrm{H}$ and ${ }^{13} \mathrm{C}$ of CSP-2

The strong and wide band near $3378 \mathrm{~cm}^{-1}$ represents the $\mathrm{O}-\mathrm{H}$ stretching vibration of water or carboxylic acid, and the relatively weak absorption peaks located at $2937 \mathrm{~cm}^{-1}$ and $1371 \mathrm{~cm}^{-1}$ are due to $\mathrm{C}-\mathrm{H}$ stretching and bending vibrations. Moreover, the bands at $1615 \mathrm{~cm}^{-1}$ and $1417 \mathrm{~cm}^{-1}$ are associated with asymmetric and symmetric stretching vibrations, respectively, of free carboxylate groups. The peak at $1745 \mathrm{~cm}^{-1}$ suggests the 
existence of $\mathrm{C}=\mathrm{O}$ in the ester carbonyl. Namely, the peaks at approximately $1745 \mathrm{~cm}^{-1}$, $1615 \mathrm{~cm}^{-1}$, and $1417 \mathrm{~cm}^{-1}$ indicate the presence of uronic acid, which again confirms the data obtained by the monosaccharide analysis. Usually, the ratio of band areas between $1745 \mathrm{~cm}^{-1}$ and $1615 \mathrm{~cm}^{-1}$ (R1745 per 1615) presents the degree of esterification (DE) (Pappas et al. 2004). In Fig. 3B, the DE value of CSP-2 was 44.6\%, which was slightly lower than that of CSP-3 (45.0\%). Polysaccharides extracted by water are usually highly methyl esterified. In the fingerprint region, a band at $1245 \mathrm{~cm}^{-1}$ would be derived from the stretching vibration of $\mathrm{C}-\mathrm{O}$ or $\mathrm{O}-\mathrm{H}$ deformation vibrations, and the small signal at $1049 \mathrm{~cm}^{-1}$ was assigned to the $\mathrm{C}-\mathrm{O}, \mathrm{C}-\mathrm{C}$ stretching, or $\mathrm{C}-\mathrm{OH}$ bending typical of arabinofuranose (Kacurakova et al. 1998). The peak at $960 \mathrm{~cm}^{-1}$ can be attributed to the skeletal mode of a pyranose ring (Zheng et al. 2015). In addition, the strong absorptions at $1147 \mathrm{~cm}^{-1}, 1103 \mathrm{~cm}^{-1}, 1012 \mathrm{~cm}^{-1}, 916 \mathrm{~cm}^{-1}$, and $765^{-1}$ are typical of the $\alpha$-pyranose form of the glucoside, while the absorption peaks at $831 \mathrm{~cm}^{-1}$ indicate that the $\beta$ configuration existed in the three polysaccharides (Luo et al. 2008; Han et al. 2016). There was a strong peak at $1103 \mathrm{~cm}^{-1}$ indicating that the glycosidic bond was primarily $\alpha$ glycosidic. The weak peak located at $896 \mathrm{~cm}^{-1}$ corresponding to the $\mathrm{C}-1$ group frequency or ring frequency, also represented the $\beta$-linkage of galactose residues (Kruse and Dinjus 2007; Azad et al. 2015). Additionally, the weak absorption at $802 \mathrm{~cm}^{-1}$ established the presence of a small amount of mannose. The two acidic fractions had many typical characteristics of pectin, and they were rich in uronic acid and methyl groups to varying extents.

\section{Glycosidic Linkage Analysis}

Homogeneous polysaccharide (CSP-2) with the stronger antioxidant activity was selected (as shown below) for methylation and NMR analysis to elucidate its structural characterization. To elucidate the linkages of CSP-2, the methylated product was analyzed by GC-MS. The molar ratio of each linkage residue was calculated from the peak area in the total ion chromatogram and the molecular weight of PMAAs. The analysis results are presented in Table 2 . The methylation data indicated that there were many 1,4-D-GalpA units on the CSP-2 backbones. The acidic fractions consisted of large amounts of GlapA, where more than $80.2 \%$ of GlapA was 1,4-linked, indicating large amounts of homogalacturonan. 1,4-D-Gal $p$ was the second most abundant glycosidic linkage, with a content of $25.7 \%$. Most of the Galp (91.7\%) was 1,4-linked. Approximately $5.0 \%$ of Gal $p$ was found to be terminal-linked (T-linked), and $3.3 \%$ was 1,6-linked. Thus, galactose residues were supposed to mostly be present as 1,4-Dgalactans. In addition, Ara was found to include T-, 3-, 4-, 5-, and 3,4-linked furanosyl or pyranoid units. $48.2 \%$ of Ara was 1,5-L-Araf, which suggested the presence of arabinan or arabinogalactan. Small amounts of rhamnose derivatives demonstrated the presence of 1,2,4-L-Rhap units. According to the ratio of Rha per 1,4-GalpA, approximately 5.4\%, rhamnogalacturonan-I (RG-I) might be attached to an HG backbone (Schols and Voragen 1996). The primary terminal residues of CSP-2 were T-L-Arap (1.2\%), T-L-GalpA $(6.9 \%)$, and T-D-Galp (1.4\%). Moreover, there was a fair amount of 1,3-L-Araf, 1,4-LArap, 1,3,4- L-Arap, and 1,6-D-Galp residues, which were probably incorporated randomly in the side chains. These results are consistent with data from the FTIR and monosaccharide composition analysis. 
Table 2. Results of the Methylation Analysis of CSP-2

\begin{tabular}{|c|c|c|c|}
\hline NO. & Methylated Sugars & Deduced Linkage & Relative Amount (mol \%) \\
\hline A & 2,3,5-Me - -Araf & T-linked Araf & 1.9 \\
\hline B & 2,5-Me2-Araf & 1,3-linked Araf & 2.2 \\
\hline C & 2,3-Me-Araf & 1,5-linked Araf & 9.5 \\
\hline D & 2,3,4,6-Me4-d-Galp & T-linked Galp & 2.2 \\
\hline E & 2-Me-Arap & 1,3,4- linked Arap & 2.4 \\
\hline F & 3-Me-Rhap & 1,2,4-linked Rhap & 3.6 \\
\hline G & 2,3,6-Me3-Galp & 1,4-linked GalAp & 66.2 \\
\hline H & 2,3,4-Mes-Galp & 1,6-linked Galp & 1.4 \\
\hline I & 2,3-Me2-Arap & 1,4-linked Arap & 3.8 \\
\hline J & 2,4-Me2-Glup & 1,3,6-linked Glup & 6.8 \\
\hline
\end{tabular}

\section{NMR Analysis}

To further confirm the linkage sites of CSP-2, ${ }^{1} \mathrm{H}$ and ${ }^{13} \mathrm{C}$ NMR studies were conducted. The spectrograms shown in Fig. 3C and D were analyzed as completely as possible according to monosaccharide composition analysis, glycosidic linkage analysis, and reports in the literature. The signals in the range of 4.9 to $5.1 \mathrm{ppm}$ and 4.4 to $4.6 \mathrm{ppm}$ represent $\alpha$-glycosidic and $\beta$-glycosidic configurations. The strong response at $\delta_{\mathrm{H}}$ greater than $5.0 \mathrm{ppm}$ clearly demonstrated that the glycosidic bond in CSP-2 was primarily $\alpha$ glycosidic. Two signals were observed at $\delta_{\mathrm{H}} 5.09 \mathrm{ppm}(\mathrm{H}-1)$ and $\delta_{\mathrm{H}} 5.03 \mathrm{ppm}(\mathrm{H}-5)$, belonging to nonesterified galacturonic acid residues. The signal at $4.90 \mathrm{ppm}$ could be assigned to the presence of esterified GalpA (Sharma et al. 2015; Wang et al. 2016). This finding further confirmed the presence of Gal $p \mathrm{~A}$ with an $\alpha$-glycosidic linkage. The signals in the range of $\delta_{\mathrm{H}} 3.2$ to 4.5 should be assigned to $\mathrm{H}-2$ to $\mathrm{H}-5$ (or H-6) of the glycosidic group. The three major signals from 3.6 to $4.5 \mathrm{ppm}$ were assigned as the $\mathrm{H}-2$ (3.70 ppm), H-3 (3.94 ppm), and H-4 (4.40 ppm) atoms of 1,4- $\alpha-\mathrm{D}-\mathrm{Gal} p \mathrm{~A}$. The strong signals at $\delta_{\mathrm{H}} 3.74$ were derived from terminal protons of methoxyl groups, and the weak signals at $2.12 \mathrm{ppm}$ and $2.01 \mathrm{ppm}$ might be attributed to the bending of acetyl groups (Winning et al. 2007; Popov et al. 2014). 1,2,4-L-Rhap residues contributed to weak peaks at 1.11 to $1.25 \mathrm{ppm}$. The other two weak signals at $5.25 \mathrm{ppm}$ and $3.29 \mathrm{ppm}$ belonged to the H-1 and $\mathrm{H}-4$ of Rhap, respectively. The uronic acid could be confirmed by chemical shifts appearing at 5.73 and $6.05 \mathrm{ppm}$. A resonance of $1,4-\beta-\mathrm{D}-\mathrm{Gal} p$ was also found at $4.07 \mathrm{ppm}$ and $4.16 \mathrm{ppm}$, arising from $\mathrm{H}-6$ and $\mathrm{H}-4$, respectively (Gong et al. 2016; Cantu-Jungles et al. 2017).

${ }^{13} \mathrm{C}$ NMR spectra had a higher resolution when compared to ${ }^{1} \mathrm{H}$. Most chemical shifts in the region from $98 \mathrm{ppm}$ to $101 \mathrm{ppm}$ were attributed to the $\alpha$-anomeric carbon. The strong signals at $\delta 100.41$ and $\delta 99.46$ were ascribed to the $\mathrm{C}-1$ of methyl-esterified and non-esterified 1,4- $\alpha$-D-GalpA, respectively. Signals corresponding to C-6 appeared at $175.21 \mathrm{ppm}$ and $170.76 \mathrm{ppm}$. Proton signals of C-2, C-3, C-4, and C-5 appeared at 68.04 ppm, $70.58 \mathrm{ppm}, 78.93 \mathrm{ppm}$, and $71.53 \mathrm{ppm}$, respectively. The chemical shifts between 78 to $80 \mathrm{ppm}$ could be interpreted as arising from the C-4 substitutions. In the high field region, the carbon signal at $\delta 52.96 \mathrm{ppm}$ confirmed the presence of esterified carboxyl groups of GalpA residues, and the signal at $20.23 \mathrm{ppm}$ was assigned to $\mathrm{CH}_{3}$ in acetyl groups (data not shown). Moreover, the C-1 NMR region also contained signals at 77.75 
ppm, 76.80, and $61.13 \mathrm{ppm}$ from 1,4-D-Galp units. Signals at $107.52 \mathrm{ppm}$ and 103.11 ppm might be assigned to the C-1 of L-Ara and $\beta$-D-Galp (substituted at $O-6$ ). All the above assignments were consistent with published values (Chen et al. 2010; Zheng et al. 2015; Han et al. 2016). This result was also consistent with the analysis of the FTIR spectrometric data.

\section{Antioxidant Activity in vitro}

Scavenging of hydroxyl radical

The hydroxyl radical is quite toxic to living organisms due to its reaction with all functional biomacromolecules. Hydroxyl radical activity results in cancer, aging, and overall degenerative damage. Hydroxyl radicals are mostly produced from the decomposition of hydroperoxides. The scavenging hydroxyl radical abilities of CSP, CSP-1, CSP-2, CSP-3, and $\mathrm{V}_{\mathrm{C}}$ are shown in Fig. 4A. Their activity was concentration dependent. CSP showed almost no scavenging capacity at a low dosage, but this capacity increased quickly at higher concentrations reaching $27.2 \%$ at $2 \mathrm{mg} / \mathrm{mL}$. Among the three purified polysaccharides, CSP-2 possessed the highest $\mathrm{OH}$ scavenging activity of $28.0 \%$ at $2 \mathrm{mg} / \mathrm{mL}$, but the scavenging capacity of CSP-1 was significantly lower than that of CSP-2. Overall, pectic polysaccharides from FCS are superior to crude and neutral polysaccharides with respect to eliminating $\mathrm{OH}$ radicals.

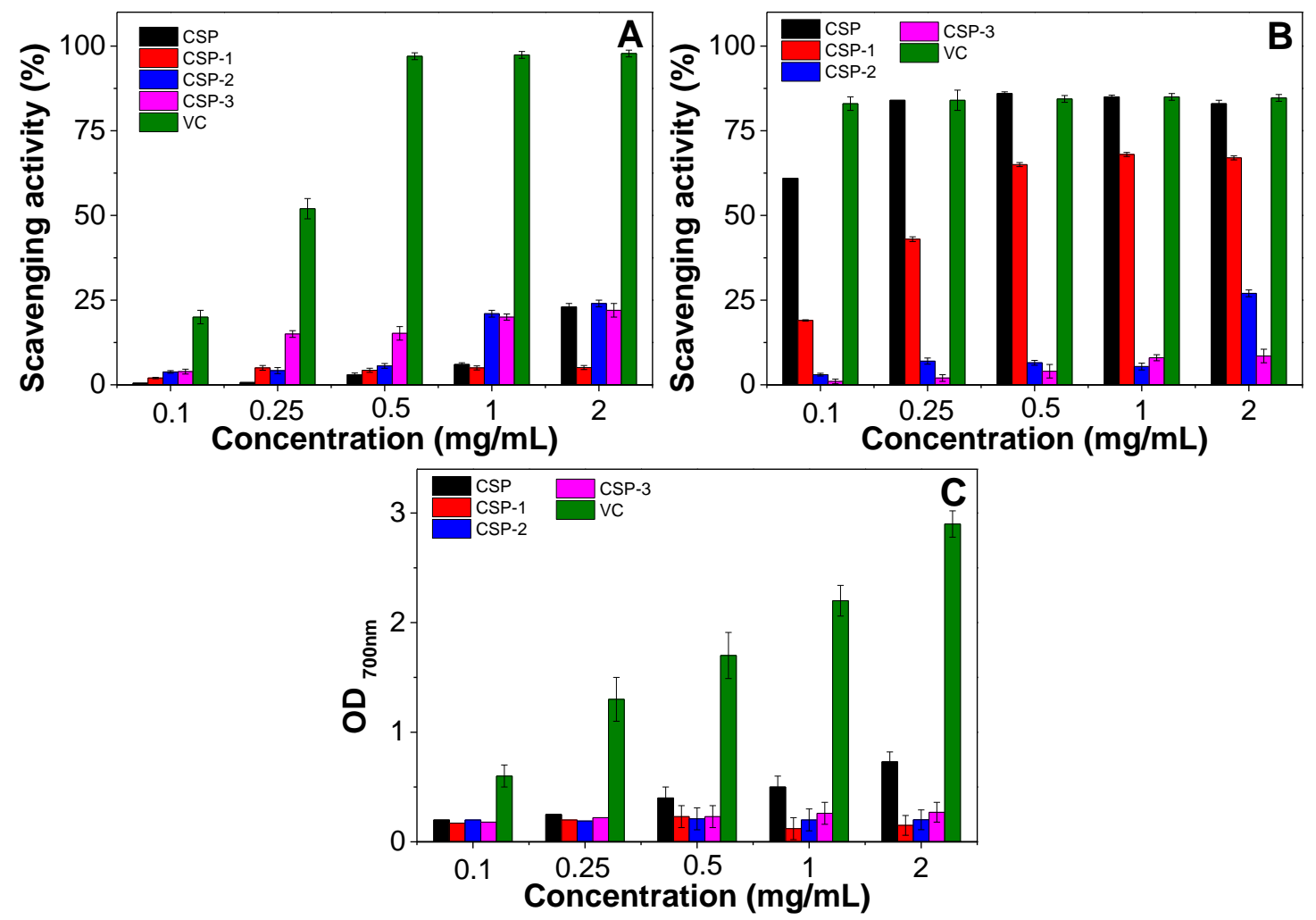

Fig. 4. Antioxidant activity in vitro: (A) Scavenging of hydroxyl radical; (B) Scavenging of DPPH radical; (C) Reducing power

\section{Scavenging of the DPPH radical}

DPPH has been widely used in antioxidant assays due to the convenience of procedures and the reproducibility of results. DPPH is a free radical compound exhibiting 
a characteristic absorption at $517 \mathrm{~nm}$. This absorption (visible as a purple color) fades significantly upon exposure to a proton radical scavenger. As shown in Fig. 4B, the scavenging abilities of the three CSP polysaccharides were found to be ranked in the following order: CSP is greater than CSP-1, CSP-1 is greater than CSP-2, and CSP-2 is greater than CSP-3. The differences among them might arise from a variety of causes, including the variation in monosaccharide content and/or phenolic compounds, conformation, or molecular weight. Extraction methods could also influence results, as seen in previous studies. At concentrations from $0.1 \mathrm{mg} / \mathrm{mL}$ to $1 \mathrm{mg} / \mathrm{mL}$, the DPPH radical scavenging activity increased with concentration. The DPPH scavenging abilities slightly increased when the concentration exceeded $1 \mathrm{mg} / \mathrm{mL}$. In addition, CSP developed significant DPPH scavenging activity which was equal to $\mathrm{V}_{\mathrm{C}}$ at dosages from $0.25 \mathrm{mg} / \mathrm{mL}$ to $2 \mathrm{mg} / \mathrm{mL}$. The activity reached a plateau of approximately $85.4 \%$ above $0.25 \mathrm{mg} / \mathrm{mL}$. It was obvious that CSP exhibited high DPPH scavenging ability and could be explored as a new antioxidant in anti-cancer therapies and treatments.

\section{Reducing power assay}

The potassium ferricyanide reduction method was used to assess the reductive activities of samples and Vc, with an observed dose-dependent response as shown in Fig. 4C. During the testing, ferricyanide is reduced to ferrous iron. At concentrations of 0.1 $\mathrm{mg} / \mathrm{mL}$ and $0.25 \mathrm{mg} / \mathrm{mL}$, the four samples had almost the same optical density (OD) of approximately 0.18 . CSP showed the highest reducing power at a high concentration. However, there were no obvious changes when the concentrations of the further purified polysaccharides increased. These results suggest the presence of additional phytochemicals. In summary, CSP expressed stronger abilities both in eliminating DPPH radicals and in reducing the three purified polysaccharides. Hence, the detailed defense mechanism of CSP in FCS, as a potential antioxidant, necessitates further investigation.

\section{CONCLUSIONS}

1. Moderate temperature $\left(150{ }^{\circ} \mathrm{C}\right)$ and a short extraction time $(45 \mathrm{~min})$ at a solid to liquid ratio of 1 to $10 \mathrm{~g} / \mathrm{mL}$ were found to be effective in obtaining high $\mathrm{P}_{\mathrm{A}}$ yields from the fruits of Chaenomeles sinensis.

2. A neutral (CSP-1) and two acidic polysaccharides (CSP-2, CSP-3) were separated by DEAE-52 and characterized. The two acidic fractions showed typical characteristics of methylated pectins and exerted remarkable antioxidant ability in scavenging hydroxyl radicals.

3. The backbone of CSP-2 was found to contain primarily 1,4- $\alpha$-galacturonans with RGI insertions. The side chains attached to the 4-position of the 1,2-L-Rhap residues in the RG region appeared to include primarily 1,4-galactans and to a lesser extent, 1,5Araf and 1,3,4-Galp.

4. In summary, these polysaccharides are natural antioxidants, and the ripe fruit of Chaenomeles sinensis (FCS) appears to be a promising source of pectin for commercial applications due to its rich raw materials and simple extraction method. 


\section{ACKNOWLEDGEMENTS}

The authors gratefully acknowledge the financial support provided by the Program for Henan Scientific and Technological Innovation Talents of Colleges and Universities (19HASTIT012).

\section{REFERENCES CITED}

Al-Sheraji, S. H., Ismail, A., Manap, M. Y., Mustafa, S., Yusof, R. M., and Hassan, F. A. (2012). "Purification, characterization and antioxidant activity of polysaccharides extracted from the fibrous pulp of Mangifera Pajang fruits," LWT-Food Science and Technology 48(2), 291-296. DOI: 10.1016/j.lwt.2012.04.002

Alvira, P., Tomás-Pejó, E., Ballesteros, M., and Negro, M. J. (2010). "Pretreatment technologies for an efficient bioethanol production process based on enzymatic hydrolysis: A review," Bioresource Technology 101(13), 4851-4861. DOI: 10.1016/j.biortech.2009.11.093

Azad, M. A. K., Wang, F., and Kim, H. R. (2015). "Identification of a novel sugar compound from Korean pine seeds," Food Science and Technology 24(6), 20112015. DOI: 10.1007/s10068-015-0265-y

Cantu-Jungles, T. M., Cipriani, T. R., Iacomini, M., Hamaker, B. R., and Cordeiro, L. M. (2017). "A pectic polysaccharide from peach palm fruits (Bactris gasipaes) and its fermentation profile by the human gut microbiota in vitro," Bioactive Carbohydrates and Dietary Fiber 9, 1-6. DOI: 10.1016/j.bcdf.2016.11.005

Chen, F., and Huang, G. (2018). "Extraction and antioxidant activities of cushaw polysaccharide," International Journal of Biological Macromolecules 120, 16461649. DOI: $10.1016 /$ j.ijbiomac.2018.09.200

Chen, X., Lawoko, M., and Heiningen, A. (2010). "Kinetics and mechanism of autohydrolysis of hardwoods," Bioresource Technology 101(20), 7812-7819. DOI: 10.1016/j.biortech.2010.05.006

Fagioli, L., Pavoni, L., Logrippo, S., Pelucchini, C., Rampoldi, L, Cespi, M., Bonacucina, G., and Casettari, L. (2019). "Linear viscoelastic properties of selected polysaccharide gums as function of concentration, $\mathrm{pH}$, and temperature," Journal of Food Science 84 (1), 65-72. DOI: 10.1111/1750-3841.14407

Ferreira, J. A., Mafra, I., Soares, M. R., Evtuguin, D. V., and Coimbra, M. A. (2006). "Dimeric calcium complexes of arabinan-rich pectic polysaccharides from Olea europaea L. cell walls," Carbohydrate Polymers 65(4), 535-543. DOI: 10.1016/j.carbpol.2006.02.013

Gong, G., Fan, J., Sun, Y., Wu, Y., Liu, Y., Sun, W., Zhang, Y., and Wang, Z. (2016). "Isolation, structural characterization, and antioxidativity of polysaccharide LBLP5-A from Lycium barbarum leaves," Process Biochemistry 51(2), 314-324. DOI: 10.1016/j.procbio.2015.11.013

Han, Y. L., Gao, L., Yin, Y. Y., Jin, Z. Y., Xu, X. M., and Chen, H. Q. (2016). "Extraction optimization by response surface methodology of mucilage polysaccharide from the peel of Opuntia dillenii Haw. fruits and their physicochemical properties," Carbohydrate Polymers 151,381-391. DOI: 10.1016/j.carbpol.2016.05.085 
Kacurakova, M., Belton, P. S., Wilson, R. H., Hirsch, J., and Ebringerova, A. (1998). "Hydration properties of xylan-type structures: An FTIR study of xylooligosaccharides," Journal of the Science of Food and Agriculture 77(1), 38-44. DOI: 10.1002/(sici)1097-0010(199805)77:1<38::aid-jsfa999>3.0.co;2-5

Kim, D. H., Lee, J. S., Yun, C. Y., Kim, D. H., and Kim, I. S. (2013). "Chinese quince (Chaenomeles sinensis) extract inhibits cell migration and cytokine release in HMC-1 cells," Food Sci. Biotechnol. 22(2), 501-506. DOI: 10.1007/s10068-013-0107-8

Kruse, A., and Dinjus, E. (2007). "Hot compressed water as reaction medium and reactant: Properties and synthesis reactions," The Journal of Supercritical Fluids 41(3), 362-380. DOI: 10.1016/j.supflu.2006.03.016

Liu, H. M., Wang, F. Y., and Liu, Y. L. (2016). "Hot-compressed water extraction of polysaccharides from soy hulls," Food Chemistry 202, 104-109. DOI: 10.1016/j.foodchem.2016.01.129

Luo, X., Xu, X., Yu, M., Yang, Z., and Zheng, L. (2008). "Characterization and immunostimulatory activity of an $\alpha-(1 \rightarrow 6)$-D-glucan from the cultured Armillariella tabescens mycelia," Food Chemistry 111(2), 357-363. DOI: 10.1016/j.foodchem.2008.03.076

Miyazawa, T., and Funazukuri, T. (2004). "Hydrothermal production of mono(galacturonic acid) and the oligomers from poly (galacturonic acid) with water under pressures," Industrial \& Engineering Chemistry Research 43(10), 2310-2314. DOI: $10.1021 / \mathrm{ie} 0202672$

Pappas, C. S., Malovikova, A., Hromadkova, Z., Tarantilis, P. A., Ebringerova, A., and Polissiou, M. G. (2004). "Determination of the degree of esterification of pectinates with decyl and benzyl ester groups by diffuse reflectance infrared Fourier transform spectroscopy (DRIFTS) and curve-fitting deconvolution method," Carbohydrate Polymers 56(4), 465-469. DOI: 10.1016/S0144-8617(04)00078-5

Pettolino, F. A., Walsh, C., Fincher, G. B., and Bacic, A. (2012). "Determining the polysaccharide composition of plant cell walls," Nature Protocols 7(9), 1590-1607. DOI: 10.1038/nprot.2012.081

Popov, S. V., Ovodova, R. G., Golovchenko, V. V., Khramova, D. S., Markov, P. A., Smirnov, V. V. Shashkov, A. S., and Ovodov, Y. S. (2014). "Pectic polysaccharides of the fresh plum Prunus domestica L. isolated with a simulated gastric fluid and their anti-inflammatory and antioxidant activities," Food Chemistry 143, 106-113. DOI: 10.1016/j.foodchem.2013.07.049

Pu, X., Ma, X., Liu, L., Ren, J., Li, H., Li, X., Yu, S., Zhang, W., and Fan, W. (2016). "Structural characterization and antioxidant activity in vitro of polysaccharides from angelica and astragalus," Carbohydrate Polymers 137, 154-164. DOI: 10.1016/j.carbpol.2015.10.053

Samavati, V. (2013). "Polysaccharide extraction from Abelmoschus esculentus: Optimization by response surface methodology," Carbohydrate Polymers 95(1), 588597. DOI: 10.1016/j.carbpol.2013.02.041

Schols, H. A., and Voragen, A. G. J. (1996). "Complex pectins: Structure elucidation using enzymes," Progress in Biotechnology 14, 3-19. DOI: 10.1016/S09210423(96)80242-5

Sharma, R., Kamboj, S., Khurana, R., Singh, G., and Rana, V. (2015). "Physicochemical and functional performance of pectin extracted by QbD approach from Tamarindus indica L. pulp," Carbohydrate Polymers 134(10), 364-374. DOI: 10.1016/j.carbpol.2015.07.073 
Wang, K. P., Wang, J., Li, Q., Zhang, Q. L., You, R. X., Cheng, Y., Luo, L., and Zhang, Y. (2014). "Structural differences and conformational characterization of five bioactive polysaccharides from Lentinus edodes," Food Research International 62, 223-232. DOI: 10.1016/j.foodres.2014.02.047

Wang, L., Liu, H. M., Xie, A. J., Zhu, C. Y., and Qin, G. Y. (2017). “Dietary fiber extraction from defatted corn hull by hot-compressed water," Polish Journal of Food and Nutrition Sciences 68(2), 133-140. DOI: 10.1515/pjfns-2017-0015

Wang, W., Ma, X., Jiang, P., Hu, L., Zhi, Z., Chen, J., Ding, T., Ye, X., and Liu, D. (2016). "Characterization of pectin from grapefruit peel: A comparison of ultrasoundassisted and conventional heating extractions," Food Hydrocolloid 61, 730-739. DOI: 10.1016/j.foodhyd.2016.06.019

Wang, X., and Lv, X. (2014). "Characterization of pectic polysaccharides extracted from apple pomace by hot-compressed water," Carbohydrate Polymers 102, 174-184. DOI: 10.1016/j.carbpol.2013.11.012

Winning, H., Viereck, N., Nørgaard, L., Larsen, J., and Engelsen, S. B. (2007). "Quantification of the degree of blockiness in pectins using ${ }^{1} \mathrm{H}$ NMR spectroscopy and chemometrics," Food Hydrocolloid 21(2), 256-266. DOI: 10.1016/j.foodhyd.2006.03.017

Xie, X., Zou, G., and Li, C. (2015). "Antitumor and immunomodulatory activities of a water-soluble polysaccharide from Chaenomeles speciose," Carbohydrate Polymers 132, 323-329. DOI: 10.1016/j.carbpol.2015.06.046

Xu, Y., Cai, F., Yu, Z., Zhang, L., Li, X., Yang, Y., and Liu, G. (2016). “Optimization of pressurized water extraction of polysaccharides from blackcurrant and its antioxidant activity," Food Chemistry 194, 650-658. DOI: 10.1016/j.foodchem.2015.08.061

Yuliansyah, A. T., Hirajima, T., Kumagai, S., and Sasaki, K. (2010). "Production of solid biofuel from agricultural wastes of the palm oil industry by hydrothermal treatment," Waste and Biomass Valorization 1(4), 395-405. DOI: 10.1007/s12649-010-9045-3

Zhao, C., Yang, R. F., and Qiu, T. Q. (2013). "Ultrasound-enhanced subcritical water extraction of polysaccharides from Lycium barbarum, L.," Separation and Purification Technology 120, 141-147. DOI: 10.1016/j.seppur.2013.09.044

Zheng, X., Liu, Z., Li, S., Wang, L., Lv, J., Li, J., Ma, X., Fan, L., and Guan, F. (2015). "Identification and characterization of a cytotoxic polysaccharide from the flower of Abelmoschus manihot," International Journal of Biological Macromolecules 82, 284 290. DOI: 10.1016/j.ijbiomac.2015.10.004

Article submitted: September 26, 2019; Peer review completed: December 1, 2019; Revised version received: December 5, 2019; Accepted: December 6, 2019; Published: December 12, 2019.

DOI: $10.15376 /$ biores.15.1.854-868 